Original Research Paper

\title{
Synthesis and Characterization of Bio-based Polyurethane Polymers
}

\author{
${ }^{1}$ Jahangir Emrani, ${ }^{2}$ Ramazan Benrashid, \\ ${ }^{3}$ Shahrzad Mohtarami, ${ }^{3}$ Ellie Fini and ${ }^{3}$ Taher Abu-Lebdeh \\ ${ }^{I}$ Department of Chemistry, North Carolina A\&T State University, \\ 1601 E. Market St., Greensboro, NC, 27411, USA \\ ${ }^{2}$ KlearOptics Corp, Kannapolis, $N C$ \\ ${ }^{3}$ Department of Civil, Architectural and Environmental Engineering \\ North Carolina A\&T State University, Greensboro, NC 27411, USA
}

Article history

Received: 06-11-2018

Revised: $16-11-2018$

Accepted: 26-11-2018

Corresponding Author:

Jahangir Emrani

Chemistry Department, North

Carolina A\&T State University,

Greensboro, NC 27411, USA

Email: emrani@ncat.edu

\begin{abstract}
This paper describes the development of new biobased Polyurethanes (PU) starting from swine manure bio-resin and diisocyanates. The bio-resin is produced from swine manure via a hydrothermal process. For sustainability, today, many PUs in new specialized applications, are biobased. In this study, different commercial diisocyanates including MDI, Desmodur W, Desmodur H and Demodur I and swine manure, which is an agricultural waste were used to make the biobased PUs. The reactions were performed at refluxing THF, or in neat form at temperatures that ranged from room temperature to $100^{\circ} \mathrm{C}$. Dibutyltin dilaurate was used as catalyst for the polymerization. Composites were characterized by FTIR, GPC, ICP and Rheometry. GPC confirmed the increase in the size of the molecules consistent with the increase in the viscosity and complex modulus of the reaction mixtures as a function of reaction time. One composite reached to elastic modulus of 10 MP at the end of the reaction process, which was marked by depletion of isocyanates peak in the IR. Progress of the polymerization reaction was monitored by the disappearance of the isocyanate band in the IR at $\sim 2274$ $\mathrm{cm}^{-1}$. By monitoring the FTIR spectra of the reaction mixtures while increasing MDI dosage in a step-wise manner, the number of the molar equivalents of the functional groups active towards isocyanate (including $\mathrm{OH}, \mathrm{H}_{2} \mathrm{~S}, \mathrm{NH}_{2}$ and $\mathrm{COOH}$ ) in the bioresin was also determined.
\end{abstract}

Keywords: Polymer, Infrared (IR) Spectroscopy, Curing, Mechanical Properties, Rheology

\section{Introduction}

Polyurethanes provide a wide range of physical and chemical properties and recyclability (Zia et al., 2007). Compared to polyesters, polyurethanes have more attractive hydrolytic and thermo-oxidative properties. With well-designed monomeric materials, PUs can be tailored to meet demands of various applications such as coatings, adhesives, fibers, thermoplastic elastomers and foams. Despite their diverse applications, PUs have low thermal stability and low mechanical strength. To overcome these and other disadvantages, effort has been devoted to the development of specialized polyurethane composites that include (PU)/montmorillonite (MMT composites), segmented polyurethanes and poly-
Polyurea Urethanes (PUUs) (Gu and Sain, 2013; Bakare et al., 2010). In some of these applications, to improve properties, bio-compatible or biobased moieties are introduced into the molecules of the PUs (Kim et al., 2016). Castor oil is one such biobased moiety that contains triglycerides with $90 \% \mathrm{C} 18$ hydroxyl fatty acid (Silva et al., 2006; Zia et al., 2007). The hydroxyl group of the ricinoleic acid reacts with the isocyanates to produce polyurethanes (Pattnaik and Nayak, 1994). To modify the properties of the biobased composites, the entire matrix or its components are treated with modifiers. For example, when a wood flour composite was treated with silane or with poly( $\beta$-hydroxybutyrate)co-poly( $\beta$-hydroxyvalerate) (PHBV), the tensile modulus was increased (Srubar et al., 2012). Further, depending 
on the nature of the diol and the isocyanate segments, a thermoset or thermoplastic PU may result. If a diol $(\mathrm{OH}-$ $\mathrm{R}-\mathrm{OH}$ ) forms the soft segment but a diisocynate (NCOR-NCO), the hard segment, then, a linear thermoplastic PU is formed (Tiwari and Raj, 2015). But, if the soft and the hard segments contain poly-hydroxy and polyisocyanates in a ratio of $\mathrm{NCO}$ : $\mathrm{OH}$ higher than one, respectively, then, a thermosetting PU is formed.

Polyurethanes that contain long flexible chains as part of their structure have flexible molecules. For example, Pus that are made with castor oil which contains several $\mathrm{OH}$ groups in its long chain, produce a flexible polymer. In terms of stability, PUs generated by the reaction of alkyl isocyanate and alkyl alcohols are more stable (degradation at $\sim 250^{\circ} \mathrm{C}$ ), than those made by aryl isocyanate and aryl alcohols (degradation at $\sim 120^{\circ} \mathrm{C}$ ) (Oprea, 2002). Also, according to literature, higher the HS (isocyanate) content, the less stable the PU (Špírková et al., 2011) but higher the SS (OH) content, the more stable the PU. These, possibly due to internetworking hydrogen bonds. Based on the literature, addition of siloxane or urea to the polymerization reaction mixture produces interpenetrating networks with better thermal stability (Oprea, 2002). In these reactions, in addition to acting as soft segment, the polyols also participate in the crosslinking reactions (Barrera-Rivera et al., 2014). Effect of wood which contains many $\mathrm{OH}$ groups on oil based $\mathrm{PU}$ has previously been tested (Gu and Sain, 2013). It was shown that the wood fiber improved the compressive strength of the polyurethane foam and contributed to its high decomposition temperature but its tensile strength decreased due to the formation of hard polyuria. Traditionally, epoxidized soybean oil has been used for cross linking PU polymers. Castor oil in combination with diethyl phosphate has been used to form of PUs with fire resistant properties (Zhang et al., 2014). Biobased polyurethanes (Calvo-Correas et al., 2016) have also been synthesized from oils. Preparation of bio-based PUs using oils showed that mechanical and morphology of the products depended on the overall crystallinity which itself was dependent upon the molar ratio of the components. This allowed the synthesis of biobased PUs with tailored properties. Further, to make adhesives from isocyanates, polar groups such as carboxyl functionality can be attached to the backbone of the polymers (Dittenber and GangaRao, 2012). For example, in a previous work, to turn rubber into adhesive, polar substrates containing $\mathrm{COOH}$ groups were added to the isocyanate reaction. Also, changing the ratio of $\mathrm{OH}$ to $\mathrm{NCO}$ groups affects the rate of the polymerization reaction (Arnold et al., 1956) which influenced the properties of the final product including its elasticity.

Again, Polyurethanes are one of the most versatile polymers. Their uses range from flexible foam used in the furniture, to insulation foam inside the walls and roofs of the buildings and appliances. They are also used in applications such as sole of the shoes or coatings inside the automobiles (Zia et al., 2007). To provide environmentally friendly polyurethanes, significant attempt has been made to create bio-based polyurethanes. This paper introduces biobased polyurethanes that are synthesized starting from swine manure. Each year, 1.7 billion tons of liquid swine manure is produced annually worldwide (Choudhary et al., 1996). In the US, the manure is disposed in storage lagoons. The storage lagoons often leak, accidentally pouring the waste into the drinking water systems (Jackson and Marx, 2016)). To make good use of this waste, it is heated in an enclosure which produces two major products: Biochar and bioresin (Hosseinnezhad et al., 2015). This communication presents the synthesis process for a biobased polyurethane that is made from a swine manure bioresin (Fini et al., 2011) and several diisocyanates. The resulting polymers were characterized using FTIR and GPC methods as well as rheometry.

\section{Materials and Methods}

Dibutyltin dilaurate and anhydrous Tetrahydrofuran (THF) were purchased from Sigma Aldrich. All diisocyanates including Desmodur W (dicyclohexyl methane-4, 4'-disisocyanate, Desmodur H (Hexamethylene-1, 6- disocyanate and Desmodur I (isophorone diisocyanate and MDI (diphenyl methane-4, 4'-diisocyanate) were donated by Covestro Corp. The bioresin was made from swine manure at the sustainable Infrastructure Materials Lab at North Carolina A\&T State University following the procedure from the previous study (Hosseinnezhad et al., 2015; Fini et al., 2011).

\section{Synthesis of the MDI Polyurethanes in the Presence of Solvent}

Bioresin, a black semisolid with a viscosity of 0.44 Pa.s at $135^{\circ} \mathrm{C}$ and $20 \mathrm{rpm}$ was dried in the oven for $10 \mathrm{~h}$ at $70^{\circ} \mathrm{C}$ before use. A sample $(5.042 \mathrm{~g})$ of the dried bioresin in dry tetrahydrofuran (THF) $(100 \mathrm{~mL})$ was placed in a three-necked round-bottom flask equipped with a stirrer, condenser, dropping funnel, nitrogen gas and a thermometer. Dibutyltin dilaurate (4-5 drops) was added as catalyst. Reaction mixture was maintained at reflux (ca $68^{\circ} \mathrm{C}$ ) while MDI (Table $1,0.502$ gram) in 20 $\mathrm{mL}$ THF was added in a stepwise manner at a constant stirring speed. The reaction mixtures became thicker upon addition of MDI and a solid ring appeared around the solvent edge which became wider over time. Periodically, aliquots of the dark solution was removed and analyzed by FTIR, monitoring the band at $2274 \mathrm{~cm}^{-1}$ which showed the presence of the unreacted diisocyanate in the reaction mixture. Appearance of this band indicated the progress of the PU formation reaction. 
Table 1: Information about various isocynates used in this study, provided by Covestro Corporation

\begin{tabular}{lll} 
CAS number \\
\hline
\end{tabular}

To exhaust all the reactive sites within the bioresin, additional quantities of the diisocyanate were added to the reaction mixture until no more diisocyanate was consumed based on the disappearance of the IR signal at $2274 \mathrm{~cm}^{-1}$. The entire reaction took approximately $2 \mathrm{~h}$ to complete. However, to make certain that all the reactive sites within the bioresin, have reacted, reaction was followed at room temperature for additional $24 \mathrm{~h}$. A similar procedure was followed with each of the other diisocyanates tested in this study. The goal was to prepare biobased polyurethanes starting from different diisocyanates and the bioresin. This goal was achieved as formation of polyurethanes was confirmed by ATRFT-IR which detected the urethane band at $1515 \mathrm{~cm}^{-1}$.

\section{Synthesis of BIO-Based Polyurethane Using MDI in Absence of Solvent}

Three grams of the dried bioresin ( $3 \mathrm{~g}$ ) was mixed with a $3 \mathrm{~g}$ neat samples of diisocyanates including MDI, Desmodurs W, H and I as provided by the manufacturer (Table 1). Dibutyltin dilaurate catalyst (4-5 drops) was added and the mixtures in glass watches were heated on a hot plate while stirring with a glass rod for 30-45 min at $70-100^{\circ} \mathrm{C}$. The consistency of all mixtures increased as a function of residence time. The resulting product were regularly subjected to FTIR spectroscopy where the gradual disappearance of the isocyanate band at 2274 $\mathrm{cm}^{-1}$ was monitored.

\section{Instrumentation}

\section{FT-IR Analysis: Attenuated Total Reflectance Fourier Transform Infrared Spectroscopy (ATR-FTIR)}

FTIR spectra of the reaction mixtures were recorded on FTIR Nicolet, Impact 410 spectrophotometer which was used in the absorbance mode to acquire spectra of each sample at wave numbers ranging from $4000 \mathrm{~cm}^{-1}$ to $400 \mathrm{~cm}^{-1}$. The background spectra were taken after cleaning the diamond prism with acetone. For monitoring the reactions and to verify the completion of the reaction [by following the disappearance of the free isocyanate groups (NCO), aliquots of the reaction mixtures in THF or in the neat form were splashed on the $\mathrm{KCl}$ disk and the disk was placed in the light path of the Shimadzu FTIR spectrometer for recording the spectra.

\section{Gel Permeation Chromatography (GPC)}

Molecular sizes of the polymers formed from the reaction of bioresin and isocyanates were measured using Size Exclusion Chromatography (Gel Permeation Chromatography GPC) that used Waters 2414 RI detector; Styragel HR1 SEC column $(7.8 \times 300 \mathrm{~mm})$, Waters 600-MS System controller connected to a 600mulitsolvent delivery system and 717-plus auto-sampler connected to a Dionex U120 Universal Interface. Samples $(3 \% \mathrm{w} / \mathrm{w}$ in Tetrahydrofuran, THF) were filtered using $0.45 \mu \mathrm{m}$ Millipore PTFE to remove suspended particulates; a pump flow rate of $1.0 \mathrm{~mL} / \mathrm{min}$ with THF as the carrier solvent and injection volumes of $50 \mu \mathrm{L}$ were used. The separation of multi-component mixture took place in the column. A constant flow of fresh eluent was supplied to the column via a pump. GPC separated analytes according to their molecular size. The resulting chromatographic data was processed using MATLAB based on elution time to obtain large, medium and small molecular size distribution.

\section{Oscillatory Test with Simultaneous Fourier Transform Infrared Spectroscopy}

Thermo Scientific HAAKE MARS rheometer with temperature control module combined with an Attenuated Total Reflection (ATR) cell with its own IR detector were used to track the rheological changes of the polymers while at the same time, the IR spectra of the same sample were collected to track the chemical changes. The evaluation of mechanical changes can be based on the storage modulus G' representing the elastic component of the viscoelastic properties and the loss modulus G" representing the viscous component. These two components are obtained from complex modulus $\mathrm{G}^{*}$ which is from maximum stress over maximum strain. Below, equations for G' and G" are shown. The instrument also evaluates the viscoelastic behavior of the sample based on phase angle. The phase angle $(\delta)$ is a measure of time lag between the stimulus (stress) and response (strain): 


$$
G^{\prime}=G^{*} \cos (\delta), G^{\prime \prime}=G^{*} \sin (\delta)
$$

\section{ICP Analysis}

Given that the bioresin with its biological source contains minerals that potentially affect the rate and extent of the polymerization of urethanes and the structure and properties of the resulting polymers, the minerals contained within the bioresin were measured using ICP analysis.

\section{Results and Discussion}

Here, we report the synthesis and characterization of bio-based polyurethanes from the bioresin fraction. To characterize the synthesized polymers, we use FTIR, GPC, ICP and rheometry.

\section{FTIR and Structure of Polyurethanes}

FTIR can be used to assess the progress of the reaction between the isocyanates and bioresin and to obtain information about the macroscopic structural features of the resulting bio-based polymer. The appearance of the FTIR spectrum depends on the nature of the hard domain in the PU and the extent of hydrogen bonding among its urea and urethane components. FTIR can help determine the progress of the reaction between isocyanates and bioresin by monitoring the isocyanate band at $2274 \mathrm{~cm}^{-1}$, also between the free and bound hydrogen bonds $(\mathrm{N}-\mathrm{H}$ and $\mathrm{C}=\mathrm{O})$ within the PU matrix. Both, position and intensity of the $\mathrm{N}-\mathrm{H}$ stretching are important to examine macroscopic properties of the PUs. The free N-H appears at $3450 \mathrm{~cm}^{-1}$ but hydrogen bonded $\mathrm{N}-\mathrm{H}$ appears a little lower, between $3300 \mathrm{~cm}^{-1}$ to 3320 $\mathrm{cm}^{-1}$. In polyurethane chemistry, the isocyanate segment, also called the Hard Segment (HS) is rigid and polar but the alcohol segment, also called the Soft Segment (SS) is flexible. Structure of both of these segments affect the degree of hydrogen bonding among the molecules. In the biobased PU, carbohydrates such as sugars originating from the starting bioresin contain many soft $\mathrm{OH}$ groups (HO-R-OH) and their isocyanate component contains the hard segment (Fig. 1). To follow the reaction between the isocyanates and the bioresin, the FTIR spectra of the bioresin, MDI and their reaction mixture were recorded (Fig. 2). The NCO band at approximately $2274 \mathrm{~cm}^{-1}$ confirmed the presence of NCO-terminated group in the diisocyanate. The size of the NCO band at the beginning of the reaction was large. However, the size was reduced as the reaction progressed so that it was no longer visible after the completion of the reaction. Of course, other IR bands are also undergoing changes as a function of the reaction time. These changes are visible in the sequence of IR spectra that are stacked up on top of each other (Fig. 2).

\section{Structure and Properties of PUs}

\section{Thermoplastic Vs Thermoset}

As mentioned in the introduction section, if a diol (OH-R-OH) forms the soft segment but a diisocynate (NCO-R-NCO), the hard segment, then, a linear thermoplastic PU is formed. But, if the soft and the hard segments contain poly-hydroxy and polyisocyanates in a ratio of $\mathrm{NCO}$ : $\mathrm{OH}$ higher than one, respectively, then, a thermosetting PU is formed. In the case of our bioresin, the isocyanate has two NCO groups/molecule but we don't know the number of $\mathrm{OH}$ groups in the bioresin. However, we do know the total number of moles of the functional groups that react with $\mathrm{NCO}$ including $\mathrm{OH}, \mathrm{NH}, \mathrm{NH}_{2}, \mathrm{SH}_{2}$, $\mathrm{SH}, \mathrm{COOH}$ (Fig. 3). Since the original source of the bioresin is animal feed which mostly contains proteins, carbohydrates and fat, it is safe to expect the presence of such functional groups in the bioresin also. Since carbohydrates contain many $\mathrm{OH}$ groups per molecule and presence of many $\mathrm{OH}$ groups in the soft segment is expected to lead to thermosetting PU, we expect to have formed a thermosetting polymer in our reactions which appears as a solid mass final product of the reaction. Use of cross-linkers in the polymerization reaction also leads to thermosetting polymers and in our case the $\mathrm{OH}$ groups within the bioresin structure can serve as cross-linker.

\section{Other Properties}

As discussed in the introduction section, PUs generated by the reaction of alkyl isocyanate and alkyl alcohols are more stable (degradation at $\sim 250^{\circ} \mathrm{C}$ ) than those made by aryl isocyanate and aryl alcohols (degradation at $\sim 120^{\circ} \mathrm{C}$ ). With MDI, our isocyanate is aryl but our alcohol coming from the bioresin is multifunctional that should render our molecules more stability. Hexamethylene diisocynates, being an alkyl diisocyanate, is expected to give a more stable PU with our bioresin. These, possibly due to internetworking hydrogen bonds. Accordingly, due to the presence of residual carbohydrates in the bioresin, since the $\mathrm{OH}$ content (SS) in our PUs are expected to be high, that should lead to a thermally stable polymer.

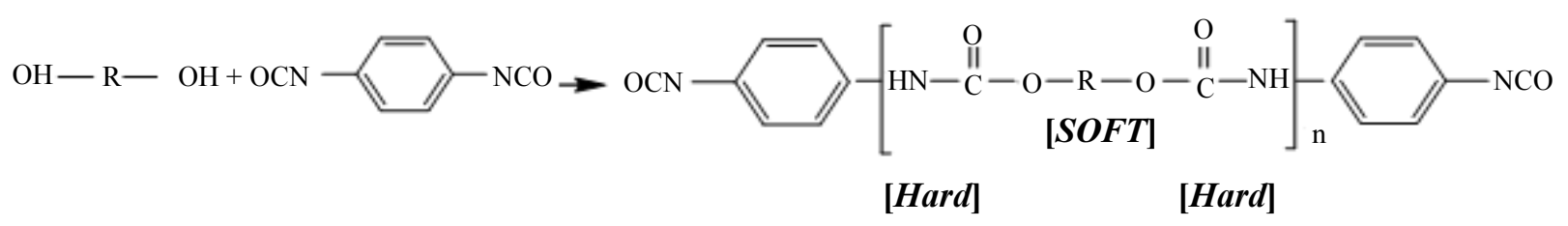

Fig. 1: General reaction between diol and diisocyanate to give Polyurethane (PU) 


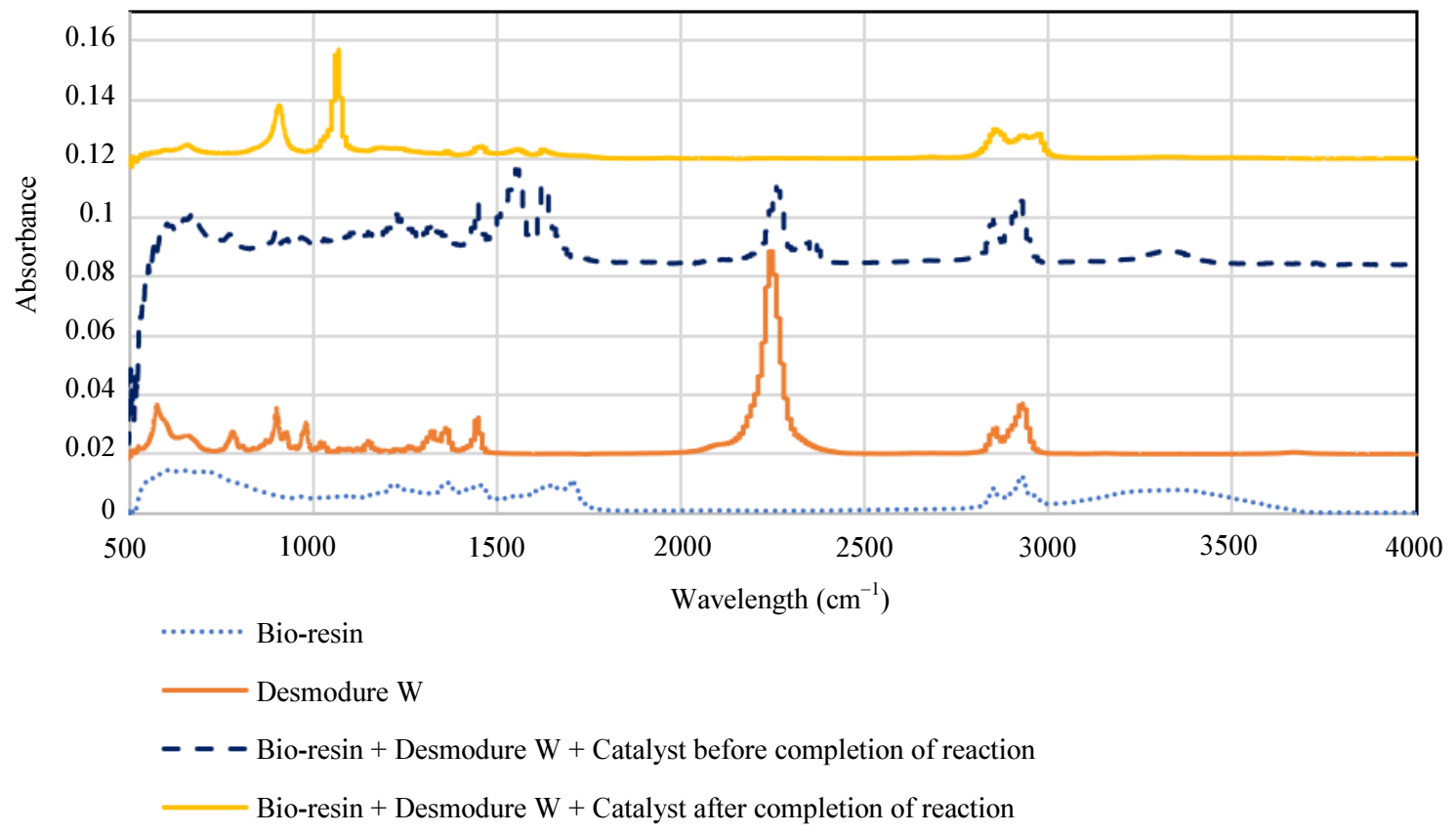

Fig. 2: FTIR of Polyurethane composite that resulted from the reaction of bioresin with Desmodure W in the presence of the catalyst

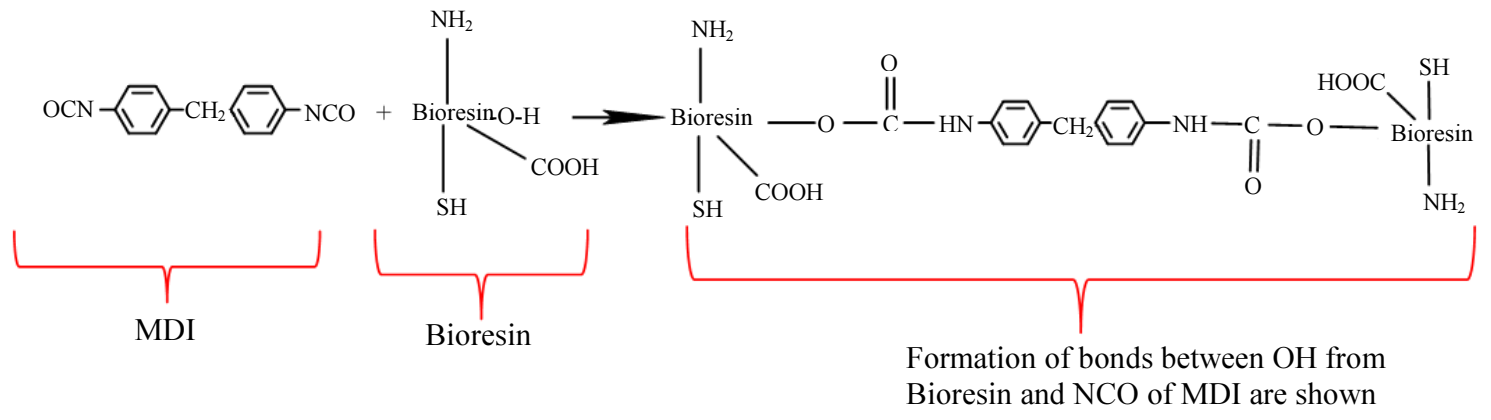

Fig. 3: Formation of bond between the $\mathrm{OH}$ group from the bioresin and the NCO group from MDI

\section{Determining the Number of Moles of Reactive Groups in the Bioresin using MDI}

The reactions between bioresin active sites and $\mathrm{NCO}$ (isocyanate) groups from MDI were used to measure the total number of active sites in the bioresin. These active sites may include $\mathrm{OH}$, but also $\mathrm{NH}_{2}, \mathrm{SH}$ and $\mathrm{COOH}$ groups. In the following reaction scheme, reaction between the two $\mathrm{NCO}$ groups of MDI and $\mathrm{OH}$ groups of the bioresin has been shown. A similar reaction can occur between the $\mathrm{NH}_{2}, \mathrm{SH}$ and $\mathrm{COOH}$ groups of the bioresin to produce the corresponding PUs of these functional groups (Fig. 3). The reaction will not distinguish between $\mathrm{NH}_{2}, \mathrm{SH}$ and $\mathrm{OH}$, but it will give the total number of moles of such reactive sites in the bioresin samples tested. Among these groups, according to literature, the primary amine $\left(\mathrm{NH}_{2}\right)$ is most reactive towards the isocyanate, followed by the primary alcohols $(\mathrm{OH})$, secondary amines $\left(\mathrm{HNR}_{2}\right)$ and other alcohols with decreased relative reactivity (Fig. 4). Table 2 shows the amount of MDI which was consumed to exhaustively react with these active sites in the bioresin as a function of time and temperature. The final number $(2.33 \mathrm{~g})$ shows the total weight of the MDI that was used to exhaustively react with 5.042 grams of the bioresin. This means that both of the NCO groups in the MDI molecule are exhaustively reacting with all the active groups that are present in the bioresin including $\mathrm{OH}, \mathrm{NH}_{2}, \mathrm{SH}$ and $\mathrm{COOH}$ groups. To calculate the number of moles of Bioresin active sites, based on the total mass of MDI 
used $(2.33 \mathrm{~g})$, knowing the molar mass of MDI (250.25 $\mathrm{g} / \mathrm{mol})$, the number of moles of MDI ( 0.0093 moles) was first calculated and since each MDI molecule contains two NCO groups, the number of moles of MDI is doubled $(0.0093 \times 2=0.0186$ moles $)$ to obtain the total moles $(0.0186$ mole $=18.6$ mmoles $)$ of bioresin active sites in the $5.042 \mathrm{~g}$ sample of bioresin:

- $\quad$ Mass of MDI used/molar mass of MDI = number of moles of MDI used

- $2 \times$ [Gram MDI/molar mass MDI $]=$ moles of Bioresin active sites

- Moles of bioresin active sites x $1000=$ number of mmoles of bioresin active sites

The corresponding FTIR spectra are shown in Fig. 5. In Fig. 5 the isocyanate band at $2274 \mathrm{~cm}^{-1}$ was large at the beginning of the reaction but its size was reduced over time as the reaction progressed. In the spectra shown in Fig. 5, the characteristic absorptions bands of the PUs at $3288 \mathrm{~cm}^{-1}$ (N-H stretching frequency), 2990-2852 $\mathrm{cm}^{-1} \quad\left(-\mathrm{CH}_{2}-\right.$ and $-\mathrm{CH}_{3}$ stretching frequencies), $1731 \mathrm{~cm}^{-1}$ (carbonyl urethane stretching), $1526 \mathrm{~cm}^{-1}$ (CHN vibration), $1223 \mathrm{~cm}^{-1}$ (coupled $\mathrm{C}-\mathrm{N}$ and $\mathrm{C}-\mathrm{O}$ stretching) and $1079 \mathrm{~cm}^{-1}$ (C-O stretching) are observed. Of course, under our reaction condition, the N-H functional groups may further react to produce biurets and other products as shown in Fig. 6. These can be compared with the FTIR spectra of the rubber seed oil-based urethane pre-polymer which showed urethane stretching $(\mathrm{N}-\mathrm{H})$ band at $3325 \mathrm{~cm}^{-1}$ and $\mathrm{N}-\mathrm{H}$ out-of-plane bending and $\mathrm{C}-\mathrm{N}$ stretching at $1538 \mathrm{~cm}^{-1}$ (Bakare et al., 2010). Here, the carbonyl stretching vibration (amide I band) of the urethane appeared at about $1737 \mathrm{~cm}^{-1}$, while the $\mathrm{NH}$ and $\mathrm{CN}$ stretching vibration (amide II bands) occurred at about 1538 and $1220 \mathrm{~cm}^{-1}$, respectively.

Comparison of the FTIR spectra of the starting bioresin with the final polymer (Fig. 5) shows that some of the characteristic absorptions of the bioresin remain unchanged in the final product. But the urethane characteristic peaks at 1732 and $1526 \mathrm{~cm}^{-1}$ are enhanced due to the formation of urethane linkages in the course of the reaction. Absence of peak at $2274 \mathrm{~cm}^{-1}$ (-NCO group) at the completion of the reaction confirms that all the MDI have been used in the reaction. These observations coupled with increased in the intensity of the NH stretching vibration at $3349 \mathrm{~cm}^{-1}$ of the product suggest bonding interaction between the components of the polymer matrix.

Table 2: Amount of bioresin and MDI, temperature and time of polymerization reaction in refluxing THF

\begin{tabular}{lllll}
\hline No. & Bio-resin weight & Gram MDI added & Reflux time & Isocyanate peak at $2274 \mathrm{~cm}^{-1}$ \\
\hline 1 & 5.042 gr constant & $0.502 \mathrm{gr}$ & $1 \mathrm{~h}$ & No \\
2 & & $0.27 \mathrm{gr}$ & $1 \mathrm{~h}$ & No \\
3 & & $0.27 \mathrm{gr}$ & $1 \mathrm{~h}$ & No \\
4 & & $0.25 \mathrm{gr}$ & $1 \mathrm{~h}$ & No \\
5 & & $0.52 \mathrm{gr}$ & $2 \mathrm{~h}$ & No \\
6 & & $0.52 \mathrm{gr}$ & $1 \mathrm{~h}$ & No \\
7 & & $1.00 \mathrm{gr}$ & Overnight RT $+8 \mathrm{~h}$ reflux & Yes \\
& & $2.33 \mathrm{gr}$ & $6 \mathrm{~h}$ & \\
\hline
\end{tabular}

Table 3: Elemental Composition of Swine manure Bioresin

\begin{tabular}{llrl}
\hline Element & ICP Wavelength monitored & $(\mathrm{ppm})$ & $(\mathrm{mg} / \mathrm{Kg})$ \\
\hline Aluminum & $\mathrm{Al} 308.215$ & 1.468 & 346.23 \\
Barium & $\mathrm{Ba} 455.403$ & 0.100 & 23.58 \\
Calcium & $\mathrm{Ca} 317.933$ & 69.060 & $16,287.74$ \\
Chromium & $\mathrm{Cr} 267.716$ & 0.028 & 6.60 \\
Copper & $\mathrm{Cu} 324.752$ & 0.954 & 225.00 \\
Iron & Fe 238.204 & 7.923 & $1,868.63$ \\
Potassium & $\mathrm{K} 766.490$ & 2.671 & 629.95 \\
Magnesium & $\mathrm{Mg} 280.271$ & 40.150 & $9,469.34$ \\
Manganese & $\mathrm{Mn} 257.610$ & 1.468 & 346.23 \\
Sodium & $\mathrm{Na} 589.592$ & 4.169 & 983.25 \\
Nickel & $\mathrm{Ni} 221.648$ & 0.058 & 13.68 \\
Phosphorus & $\mathrm{P} 213.617$ & 70.380 & $16,599.06$ \\
Sulfur & $\mathrm{S} 180.669$ & 13.860 & $3,268.87$ \\
Selenium & $\mathrm{Se} 203.985$ & 0.067 & 15.80 \\
Silicon & $\mathrm{Si} 288.158$ & 17.210 & $4,058.96$ \\
Tin & $\mathrm{Sn} 238.485$ & 2.756 & 650.00 \\
Strontium & $\mathrm{Sr} 421.552$ & 0.165 & 38.92 \\
Zinc & Zn 213.857 & 5.572 & $1,314.15$ \\
\hline
\end{tabular}




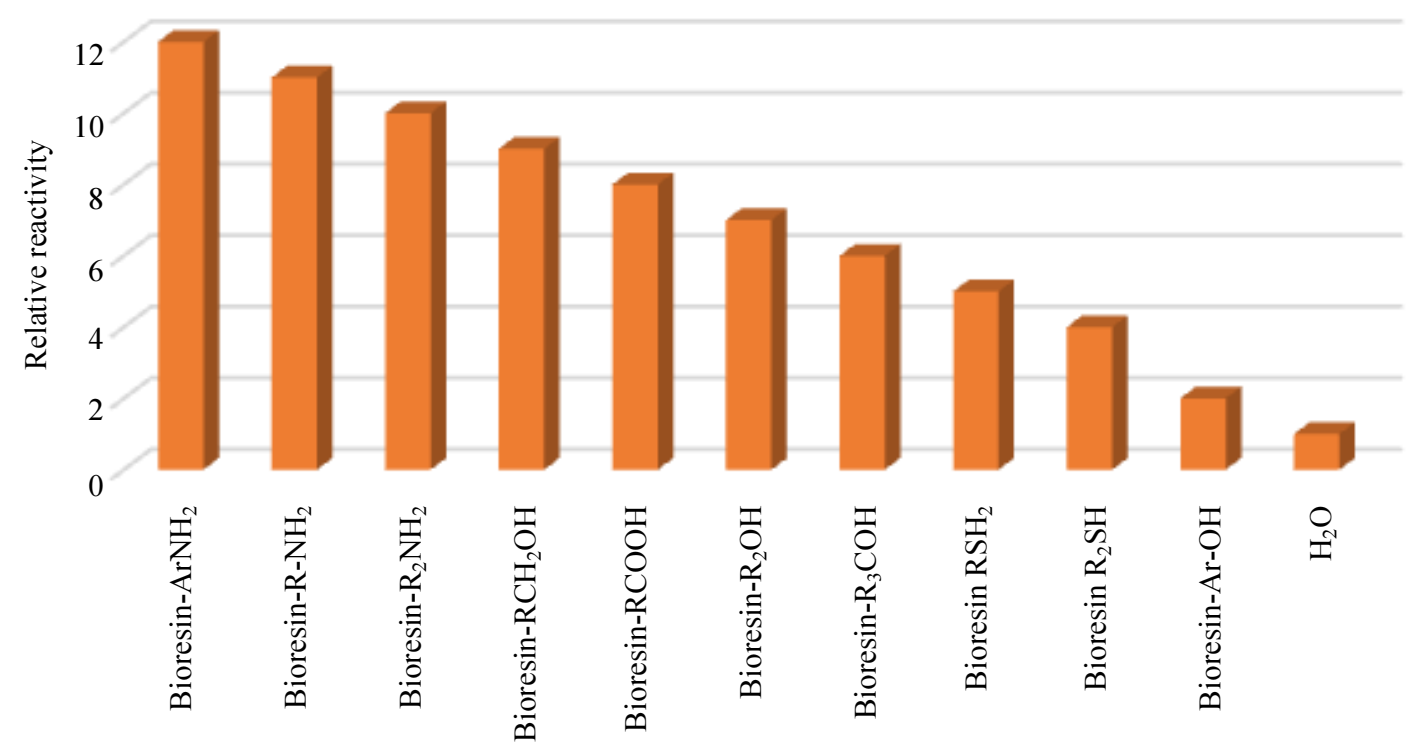

Fig. 4: Relative reactivity's of various functional groups towards isocyanates

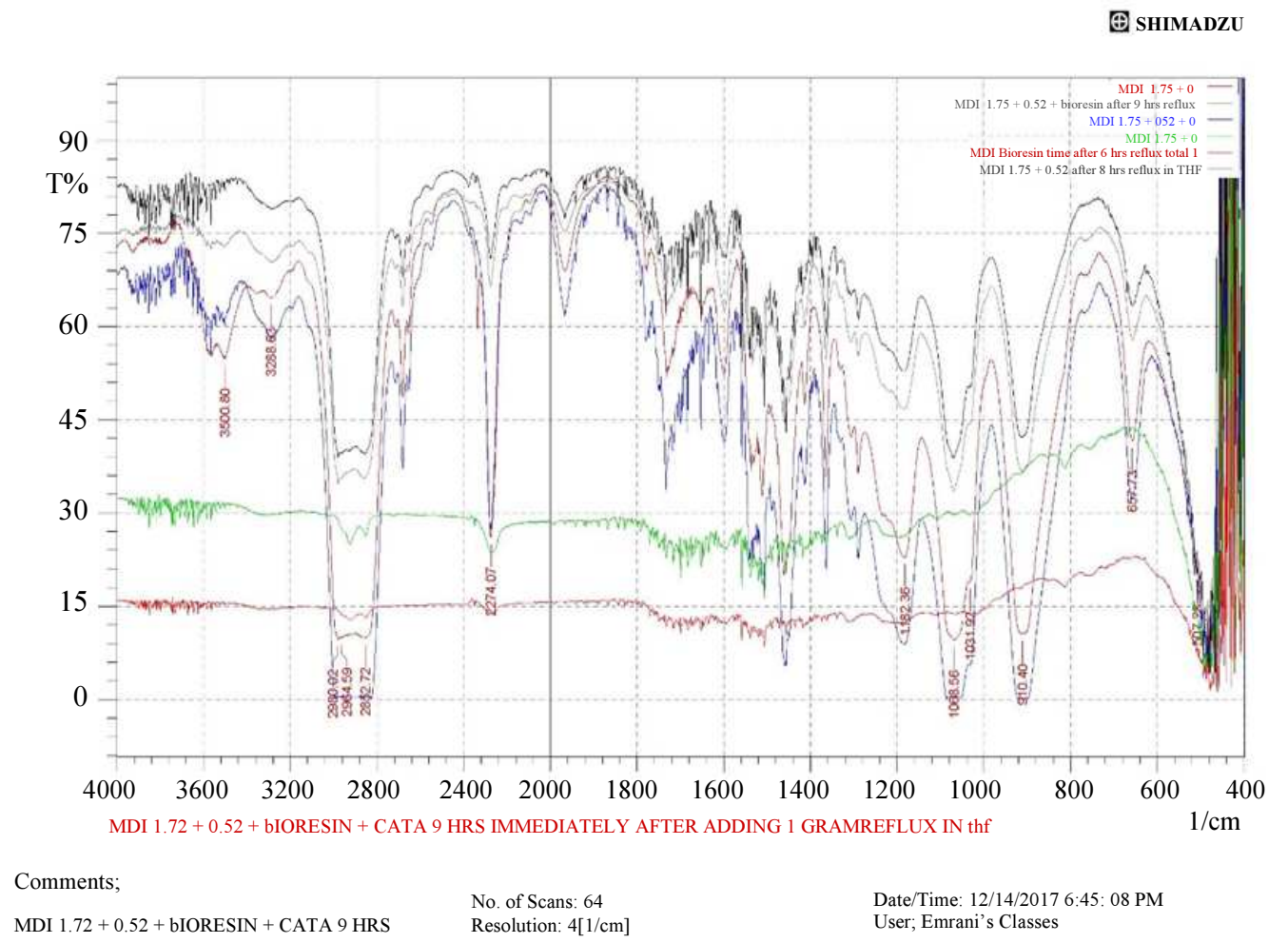

Fig. 5: Reaction of MDI with bioresin; followed by FTIR

\section{ICP and GPC Analysis}

In addition to the salts of the tin such as dibutyl tin dilaurate, salts or ions of other elements are also able to catalyze the isocyanate reactions. For this reason, the type and the quantity of the major non-carbon elements that are present in the bioresin were measured using ICP analysis (Table 3). Based on this 
analysis, the elements with the highest abundances were found to be phosphorous at $70 \mathrm{ppm}$ and calcium at $69 \mathrm{ppm}$. Magnesium was present at $40 \mathrm{ppm}$, silicon at 17 and sulfur $13 \mathrm{ppm}$. Among these, silicon, sulfur and phosphorous are able to bind with polyurethane through the bioresin polymerization and in the IR spectra, there are indication of such binding (PO stretch, Si-O-Si N-O, stretched at 1031, 1065) N-O symmetric stretch at $1400 \mathrm{~cm}^{-1}$.

\section{GPC Analysis of the Bioresin and the Composites}

Gel permeation chromatograms of the THF soluble portion of the synthesized polyurethanes compared to the bioresin show an increase in the molecular size of the bioresin components after polymerization. All polyurethanes have shown increased molecular sizes; MDI-bioresin composite could not be analyzed with GPC because the composite turned into a solid mass with very small amount soluble in THF which was not representative and was not analyzed by GPC. The largepart of the solid that was not soluble in THF must have large molecular sizes which precluded the dissolution. The results (Fig. 6) of the GPC analysis is consistent with the formation of macromolecules during the polymerization. This result is also consistent with the increase in the viscosity and eventual solidification of the reaction mixture as a function of time.

\begin{tabular}{lllll}
\hline Sample ID & BR & B-MBR & A-MBR & H-MBR \\
\hline Sample & Bio- & MDI + & MDI + & MDI + \\
Description & resin & $\begin{array}{l}\text { Bio-resin }+ \\
\text { Catalyst } \\
\text { Bio-resin }+\end{array}$ & $\begin{array}{l}\text { Bio-resin }+ \\
\text { Catalyst } \\
\text { Catalyst }\end{array}$ & $\begin{array}{l}\text { (THF reflux) } \\
\text { (THF) }\end{array}$ \\
\hline
\end{tabular}

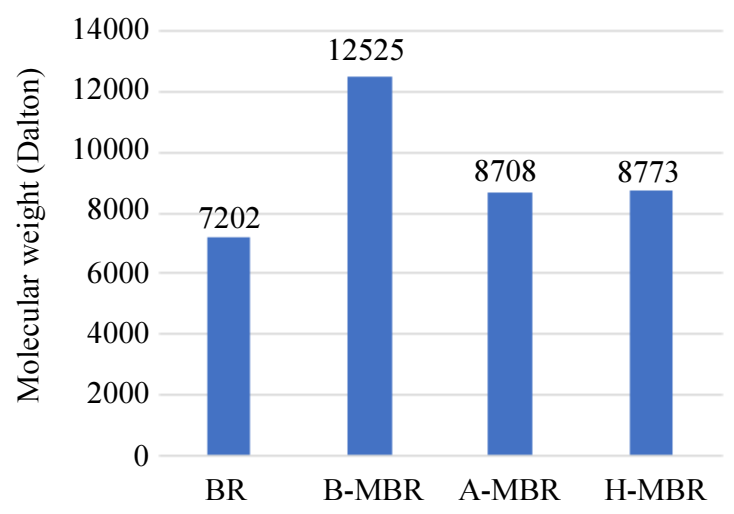

Fig. 6: GPC analysis of the mixture resulting from the reaction of MDI and bioresin

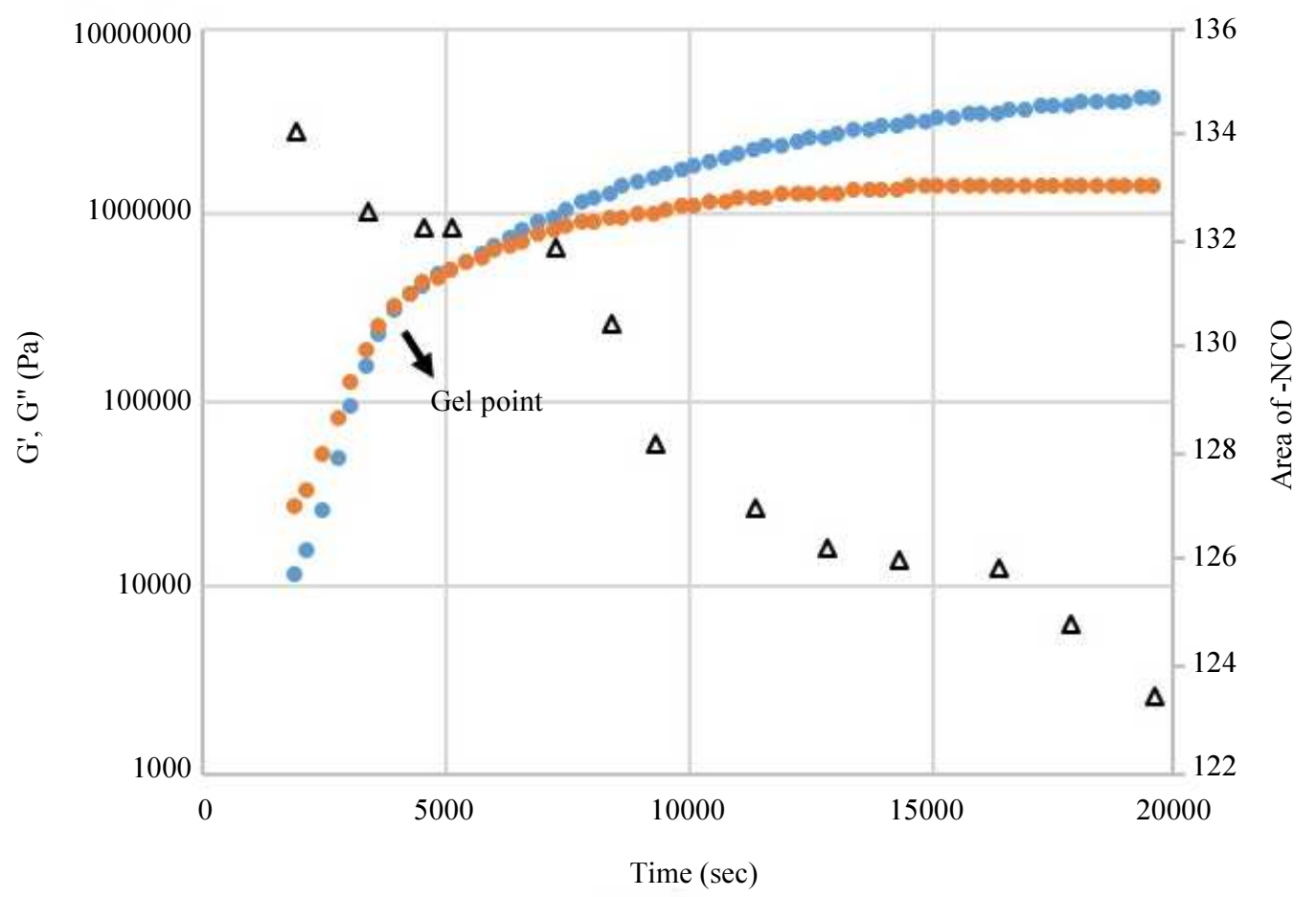

- $\mathrm{G}^{\prime}$ in $\mathrm{Pa} \quad \mathrm{G}^{\prime \prime} \quad \Delta$ Area of $-\mathrm{NCO}$

(a) 


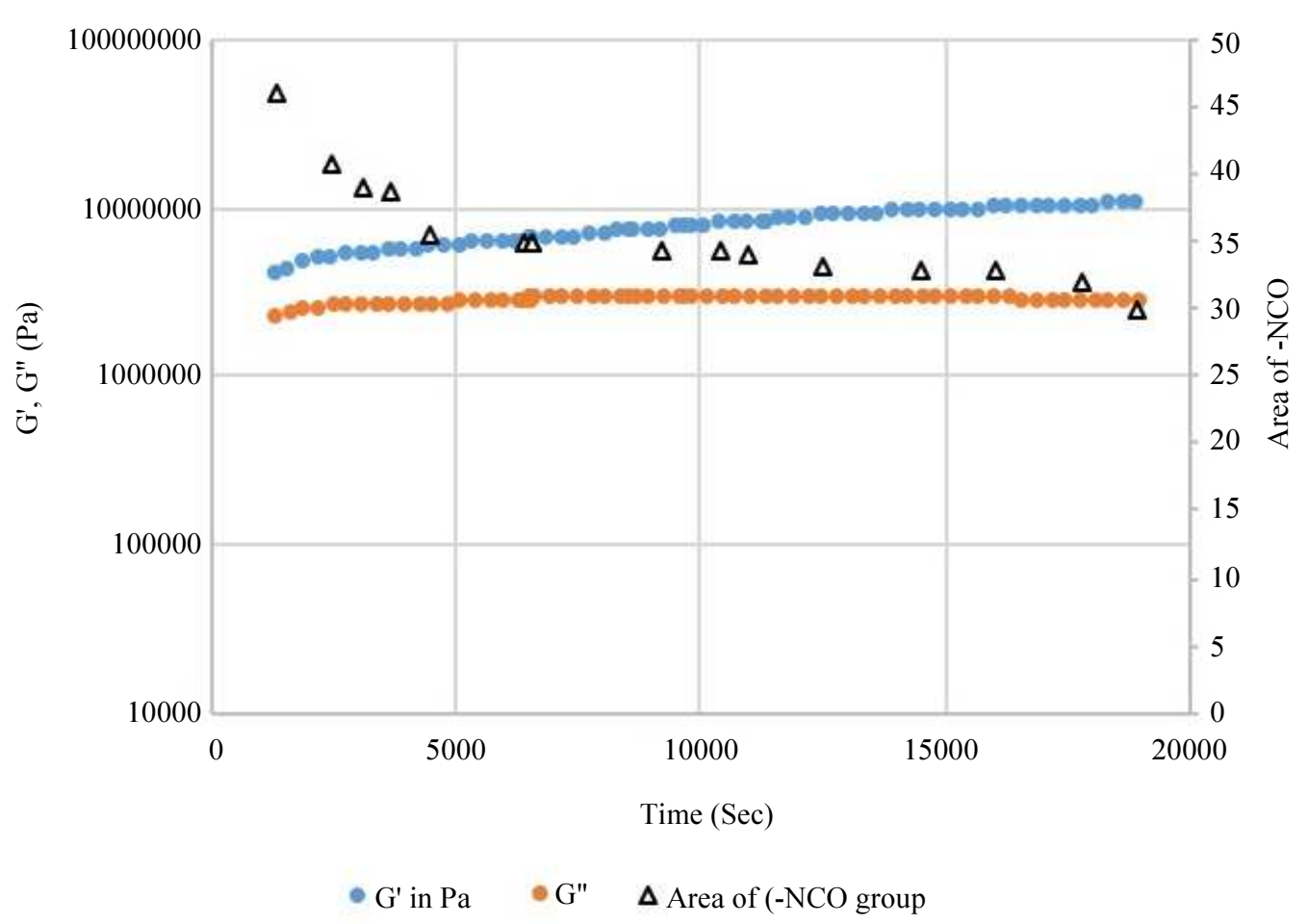

(b)

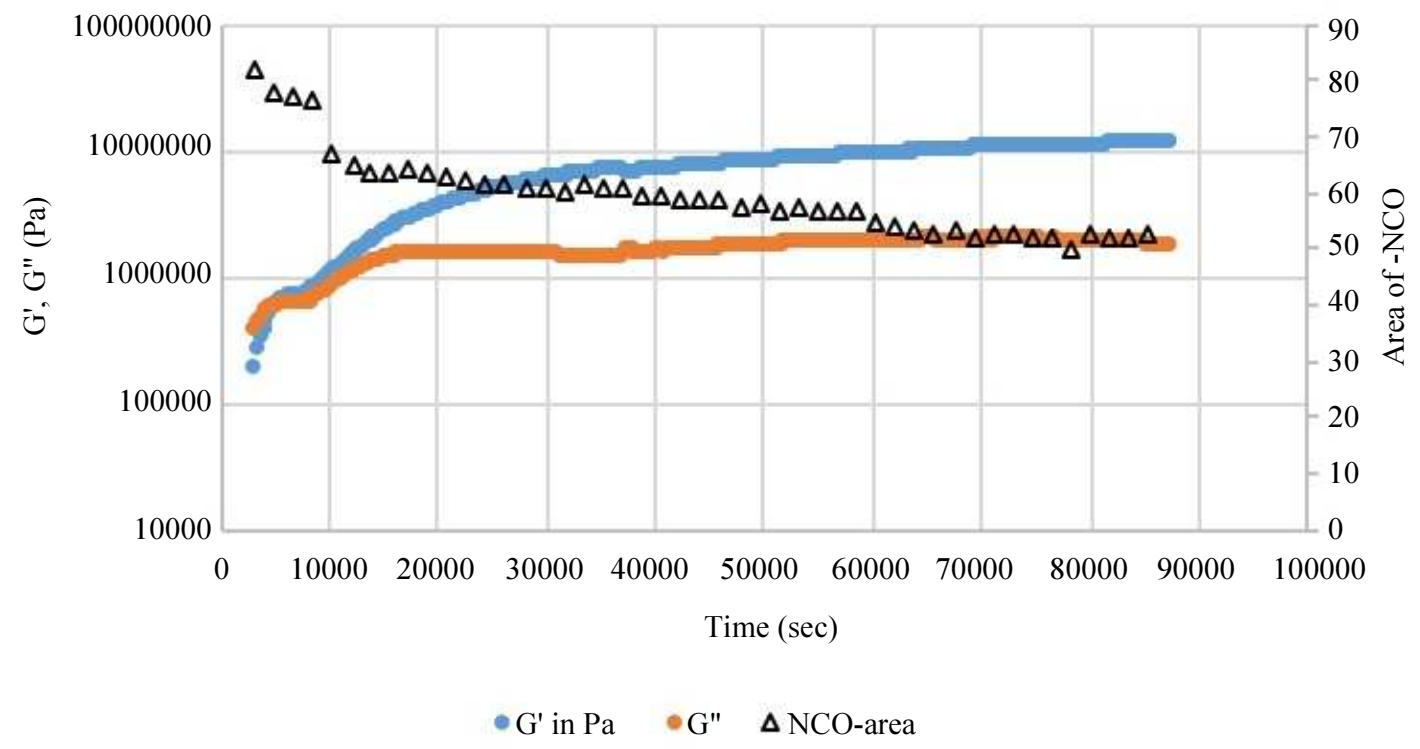

(c)

Fig. 7: Simultaneous tracking of the rheological and chemical change as a result of interaction of bio-resin, MDI and catalyst mixture at (a) $25^{\circ} \mathrm{C}$, (b) $50^{\circ} \mathrm{C}$ for $5 \mathrm{~h}$ and (c) at $25^{\circ} \mathrm{C}$ for $24 \mathrm{~h}$

\section{Rheometry Combined with In-situ Fourier Transform Infrared Spectroscopy}

Figure 7 shows the results of rheology analysis performed on PU that resulted from reaction of bioresin with MDI. Starting material and catalyst were mixed thoroughly at $50^{\circ} \mathrm{C}$ and the mixture was transferred quickly to the rheometer plate; oscillatory measurement continued for $5 \mathrm{~h}$ at $50^{\circ} \mathrm{C}$ with $10 \mathrm{rad} / \mathrm{sec}$ frequency. The results showed that due to the fast reaction between bioresin and MDI, the crossover point where $G^{\prime \prime}=G^{\prime}$ could not be captured as it occurred before the data Increase of G' over time shows progress of cross-linking which enhances the stiffness of the polymer. The storage modulus (G') is a 
measure of polymer's elastic behavior. The higher the degree of cross-linking, the higher the storage modulus. The loss modulus (G") represents viscous behavior which was found to be nearly constant during the measurement time. The simultaneous tracking of changes in chemical functional group and rheology confirmed the interaction between bio-resin and MDI. Two peaks of $2274 \mathrm{~cm}^{-1}$ and $1240 \mathrm{~cm}^{-1}$ related $-\mathrm{NCO}$ and amide group, respectively were selected for tracking the reaction. As shown in Fig. 4 , the area of peak related to - NCO group was reduced over time and it shows that MDI is consumed as it reacts with bio-resin. Enhancing amide group shows coupling the bio-resin with isocyanate structure. The rate of reduction was fast at the beginning of interaction and reached a plateau toward the end of the reaction.

\section{Chemical Reactions}

Polyurethane formation is a result of the reaction between the isocyanate group (NCO-) of the DesmodursI, $\mathrm{W}, \mathrm{H}$ and MDI and the hydroxyl $(\mathrm{OH})$, amino $\left(\mathrm{NH}_{2}, \mathrm{NH}\right)$, sulfhydryl ( $\left.\mathrm{SH}, \mathrm{H}_{2} \mathrm{~S}-\right)$, carboxyl $(\mathrm{COOH})$ and other similar reactive groups within the bioresin matrix. In fact, the observed reaction between the bioresin and isocyanates, supports the presence of these functional groups within the bioresin matrix. Qualitative relative reactivity of various possible functional groups within the bioresin with isocyanates are shown below (Fig. 5) (Himmel et al.,
1997). While reaction of isocyanate with aliphatic amines is fast, reaction of aromatic amines $\left(\mathrm{Ar}-\mathrm{NH}_{2}\right)$ with dimer of isocyanates does not occur or is expected to be very slow: $\mathrm{NH}_{2}$ reacts the fastest and water, the slowest. Despite their apparent differences, $\mathrm{OH}$ and $\mathrm{COOH}$ may have similar rates of reactions (Himmel et al., 1997). Among alkyl amines, the longer the chain, the faster the reaction. But all alkyl amines react slower than aniline which is an aromatic amine:

$$
\begin{aligned}
& \mathrm{CH}_{3} \mathrm{NH}_{2}>\mathrm{C}_{2} \mathrm{H}_{5} \mathrm{NH}_{2}>\mathrm{CH}_{3} \mathrm{OH} \\
& >\mathrm{C}_{2} \mathrm{H}_{5} \mathrm{OH}>\mathrm{CH}_{3} \mathrm{SH}>\text { pyrrole }
\end{aligned}
$$

Although at a slower rate, water can still react with the isocyanates. For this reason it was precluded from the reaction by completely drying the bioresin before the reactions. Also, all reagents used in the reaction were anhydrous and the reaction was conducted under nitrogen atmosphere. Below, possible reactions between various isocyanates (RNCO) and the active functional groups within the bioresin are shown (Fig. 8). The functional groups present in the bioresin may be part of the carbohydrates, protein and peptides, or triglycerides that may have survived the hydrothermal process used to produce the biorein which was the precursor for the PU synthesis in this paper.

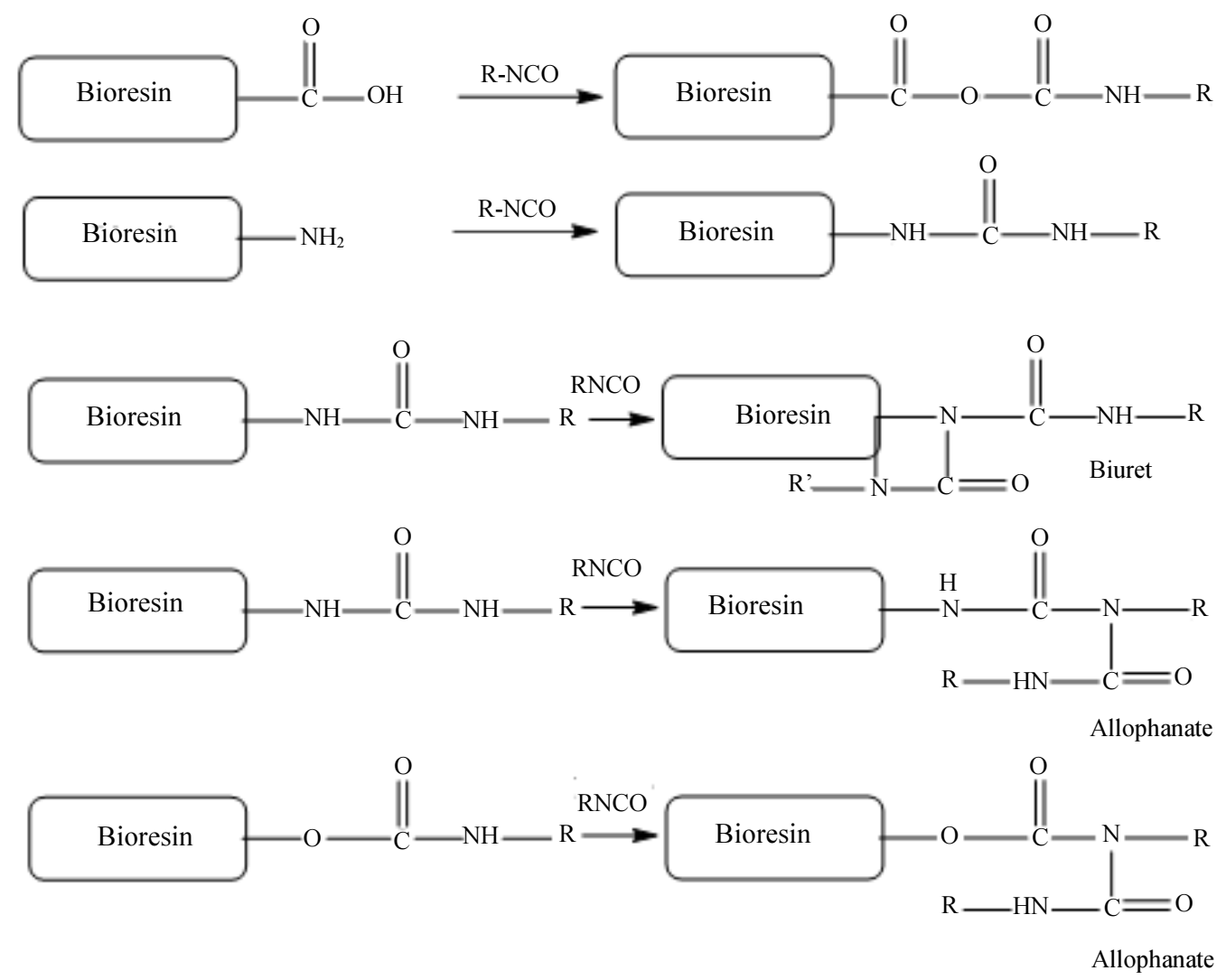

Fig. 8: Some of the possible reactions between the isocyanates and bioresin components 


\section{Conclusion}

This paper introduces an alternative bio-based Polyurethane (PU) which is made from reacting a bioresin derived from swine manure and various isocyanates. The synthesized composites were characterized by FTIR, GPC, ICP and Rheometry. Initially in the reactions, the PUs were free flowing or semisolid in texture; but as the extent of polymerization and crosslinking increased, their viscosity and complex modulus increased and the reacting mixture turned into solid substances with elastic modulus of around $10 \mathrm{MPa}$. The synthesis of polyurethane utilized the bioresin and several isocyanates including commercial hexamethylene diisocyanate (Desmodur H), dicyclohexyl methane-4,4'diisocyanate (Desmodur W), isophorone diisocyanate (Desmodur I) and Diphenyl methane-4,4'-diisocyanate (MDI). All four isocyanates successfully reacted with bioresin to create bio-based PUs. Some reactions were complete within minutes of mixing at room temperature while others required heating of up to $100^{\circ} \mathrm{C}$. All products turned into solid form upon completion of the reaction. In addition, total active sites of the bioresin was determined by monitoring the extent of reaction between MDI and bioresin. Using this method, total molar equivalents of the active functional groups (including $\mathrm{NH}_{2}, \mathrm{SH}, \mathrm{COOH}$ and $\mathrm{OH}$ ) in the bioresin was determined to be mmoles. In the future, influence of various material including wood and clay on the reaction will be tested. Clay like material (MMT) which are also expected to intercalate with our polymer will be tested.

The ratio of $\mathrm{OH}$ to $\mathrm{NCO}$ groups affects the rate of the polymerization reaction which influences the properties of the final product including its elasticity. Using this logic, it is hypothesized that addition of fatty acids and triglycerides to our bioresin composite will increase its elasticity. But addition of terminal carboxyl, or phosphoric acid groups may enhance its adhesive properties. These effects will also be tested in the future.

\section{Acknowledgement}

This research is sponsored partially by the National Science Foundation (Awards No: 1546921). The contents of this paper reflect the view of the authors, who are responsible for the facts and the accuracy of the data presented. The authors would like to thank Dr. GhasemShahbazi and Mr. Bryce Holms for providing the ICP data. Also, our thanks go to Covestro for providing the diisocyanates.

\section{Author's Contributions}

Authors participated in experimental plan and data analysis, as well as in writing the manuscript.

\section{Ethics}

No part of this article may be reproduced without written permission from the publisher or authors.

\section{References}

Arnold, R.G., J. Nelson and J.J. Verbanc, 1956. Recent advances in isocyanate chemistry. Retrieved from Wilmington.

Bakare, I.O., F.E. Okieimen, C. Pavithran, H.P.S. Abdul Khalil and M. Brahmakumar, 2010. Mechanical and thermal properties of sisal fiber-reinforced rubber seed oil-based polyurethane composites. Mater. Design, 31: 4274-4280.

DOI: $10.1016 /$ j.matdes.2010.04.013

Barrera-Rivera, K.A., L. Peponi, Á. Marcos-Fernández, J.M. Kenny and A. Martínez-Richa, 2014. Synthesis, characterization and hydrolytic degradation of polyester-urethanes obtained by lipase biocatalysis. Polymer Degradat. Stability, 108: 188-194.

DOI: 10.1016/j.polymdegradstab.2014.04.004

Calvo-Correas, T., M.D. Martin, A. Retegi, N. Gabilondo and M.A. Corcuera et al., 2016. Synthesis and characterization of polyurethanes with high renewable carbon content and tailored properties. ACS Sustainable Chem. Eng., 4: 56845692. DOI: $10.1021 /$ acssuschemeng.6b01578

Choudhary, M., L.D. Bailey and C.A. Grant, 1996. Review of the use of swine manure in crop production: Effects on yield and composition and on soil and water quality. Waste Manage. Res., 14: 581-595. DOI: $10.1177 / 0734242 X 9601400606$

Dittenber, D.B. and H.V.S. GangaRao, 2012. Critical review of recent publications on use of natural composites in infrastructure. Comp. A: Applied Sci. Manufact., 43: 1419-1429.

DOI: 10.1016/j.compositesa.2011.11.019

Fini, E.H., E.W. Kalberer, A. Shahbazi, M. Basti and Z. You et al., 2011. Chemical characterization of biobinder from swine manure: Sustainable modifier for asphalt binder. J. Mater. Civil Eng., 23: 15061513. DOI: $10.1061 /($ ASCE)MT.19435533.0000237

$\mathrm{Gu}$, R. and M.M. Sain, 2013. Effects of wood fiber and microclay on the performance of soy based polyurethane foams. J. Polymers Environ., 21: 30-38. DOI: 10.1007/s10924-012-0538-y

Himmel, H.J., K. Weiss, B. Jäger, O. Dannenberger and M. Grunze et al., 1997. Ultrahigh vacuum study on the reactivity of organic surfaces terminated by $\mathrm{OH}$ and $\mathrm{COOH}$ groups prepared by self-assembly of functionalized alkanethiols on au substrates. Langmuir, 13: 4943-4947. DOI: 10.1021/la9701211 
Hosseinnezhad, S., E.H. Fini, B.K. Sharma, M. Basti and B. Kunwar, 2015. Physiochemical characterization of synthetic bio-oils produced from bio-mass: A sustainable source for construction bio-adhesives. RSC Adv., 5: 75519-75527. DOI: $10.1039 / \mathrm{C} 5 \mathrm{RA} 10267 \mathrm{G}$

Jackson, D. and G. Marx, 2016. Spills of pig waste kill hundreds of thousands of fish in Illinois. Chicago Tribune.

Kim, G.B., J. Guo, J. Hu, D. Shan and J. Yang, 2016. Novel Applications of Urethane/Urea Chemistry in the Field of Biomaterials. In: Advances in Polyurethane Biomaterials, Guan, G. and S.L. Cooper (Eds.), Woodhead Publishing, pp: 115-147.

Oprea, S., 2002. Effect of structure on the thermal stability of curable polyester urethane urea acrylates. Polymer Degradat. Stability, 75: 9-15. DOI: 10.1016/S0141-3910(01)00200-2

Pattnaik, T. and P. Nayak, 1994. Polymers from renewable resources. II. Castor oil based interpenetrating polymer networks: Swelling behavior and scanning electron microscopy. J. Macromolecular Sci.-Pure Applied Chem.

Silva, R.V., D. Spinelli, W.W. Bose Filho, S. Claro Neto and G.O. Chierice et al., 2006. Fracture toughness of natural fibers/castor oil polyurethane composites. Comp. Sci. Technol., 66: 1328-1335.

DOI: 10.1016/j.compscitech.2005.10.012
Špírková, M., J. Pavličević, A. Strachota, R. Poreba and O. Bera et al., 2011. Novel polycarbonate-based polyurethane elastomers: Composition-property relationship. Eur. Polymer J., 47: 959-972. DOI: 10.1016/j.eurpolymj.2011.01.001

Srubar, W.V., S. Pilla, Z.C. Wright, C.A. Ryan and J.P. Greene et al., 2012. Mechanisms and impact of fiber-matrix compatibilization techniques on the material characterization of PHBV/oak wood flour engineered biobased composites. Comp. Sci. Technol., 72: 708-715.

DOI: 10.1016/j.compscitech.2012.01.021

Tiwari, A. and B. Raj, 2015. Reactions and Mechanisms in Thermal Analysis of Advanced Materials. 1st Edn., John Wiley and Sons, Hoboken, NJ, ISBN-10: 1119117704 , pp: 616.

Zhang, L., M. Zhang, L. Hu and Y. Zhou, 2014. Synthesis of rigid polyurethane foams with castor oil-based flame retardant polyols. Industrial Crops Prod., 52: 380-388.

DOI: $10.1016 /$ j.indcrop.2013.10.043

Zia, K.M., H.N. Bhatti and I. Ahmad Bhatti, 2007. Methods for polyurethane and polyurethane composites, recycling and recovery: A review. Reactive Funct. Polymers, 67: 675-692. DOI: $10.1016 /$ j.reactfunctpolym.2007.05.004 